\title{
Is there a benefit to continuing with resection of all sites of disease when clinically occult pleural metastases from non-small cell carcinoma are found?
}

\author{
Robert J. Downey, MD
}

From Memorial Sloan Kettering Cancer Center, Division of Thoracic Surgery, New York, NY.

Disclosures: Author has nothing to disclose with regard to commercial support.

Received for publication Oct 17, 2017; accepted for publication Oct 26, 2017.

Address for reprints: Robert J. Downey, MD, Memorial Sloan Kettering Cancer Center, Division of Thoracic Surgery, 1275 York Ave, New York, NY 10021-6094 (E-mail: downeyr@mskcc.org).

J Thorac Cardiovasc Surg 2018;155:1252-3

$0022-5223 / \$ 36.00$

Copyright (c) 2017 Published by Elsevier Inc. on behalf of The American Association for Thoracic Surgery https://doi.org/10.1016/j.jtcvs.2017.10.107

$\mathrm{Li}$ and colleagues ${ }^{1}$ provide a retrospective review of a single institution experience over a 7.5-year period with the management of malignant pleural implants from adenocarcinoma detected intraoperatively at the time of a planned lung cancer resection and unsuspected preoperatively. Patients who underwent resection of the pleural disease and the primary site had a better 3year overall survival $(83 \%)$ than patients who were not resected $(38 \%)$.

This is a thought-provoking study. First, the limitations need to be noted. The authors appropriately note the problem inherent to retrospective studies of determining whether patients treated differently are otherwise similar. ${ }^{1}$ They point out that the patients who did not undergo resection had a higher $\mathrm{T}$ stage and probably more extensive pleural disease, which could be markers for a more aggressive cancer. ${ }^{1}$

Second, the patient population is skewed toward women (27 of 43) and nonsmokers (32 of 43) with tumors that were positive for an epidermal growth factor receptor mutation. These factors seem to be balanced between patients undergoing resection, and those not undergoing resection. The limitation here would be in the generalizability of these findings to the much larger population with smoking-related, probably more aggressive, lung cancers.

Third, I have seen several patients in whom, at the time of exploration for resection, the lung was not adherent to the chest wall, but had invaded the visceral pleura. Directly opposite on the parietal pleura where the tumor had abutted the chest wall, there was a solitary parietal pleural implant. The authors' Figure E1 ${ }^{1}$ suggests that this might be the situation encountered during exploration of at least 1 patient in this study. I have viewed such kissing metastases as being along the scale of direct chest wall invasion (a problem of local invasion), rather than on the spectrum of diffuse pleural malignant implants (more akin to lymphatic metastases with cells following the

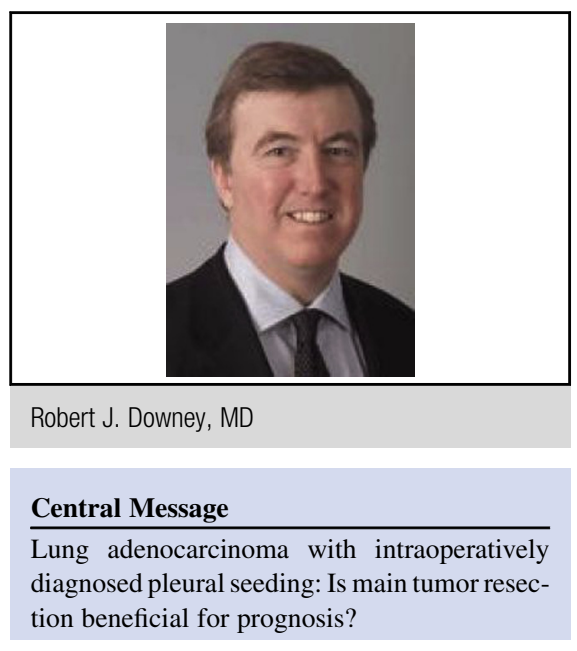

See Article page 1238.

normal physiologic flow of fluid off of the visceral pleura to be taken up by the parietal pleura). When I have encountered such kissing metastases, I have resected both the lung lesion and the chest wall implant. The current study only has 30 patients who underwent resection, and if only a few of them had kissing metastases with a possibly better prognosis, the survival of the resected patients with more diffuse pleural disease may be misleadingly elevated.

If surgical resection is actually beneficial for patients with limited pleural disease, the authors' findings ${ }^{1}$ suggest that the benefit in patients who were not cured may potentially be due to cytoreduction, so that a source of ongoing dissemination of cancer cells into both the lymphatic circulation and the bloodstream is removed. Regional progression (which I take to be lymphatic metastases) at 3 years was $61 \%$ in patients undergoing resection and $21 \%$ in unresected cases $(P=.026) .{ }^{1}$ The 3 -year probability of developing hematogenous metastases was $76 \%$ in resected cases and $23 \%$ in unresected cases, a finding that is suggestive, but did not reach statistical significance $(P=.08)$.

I am unsure how to study this question further, other than perhaps by a registry of patients from multiple institutions. The authors suggest a prospective randomized trial. This does not seem feasible for a problem that is encountered infrequently and only recognized intraoperatively—a time at which a patient can hardly give informed consent. 
In the absence of better information than retrospective studies can provide, I would not fault a surgeon who resected very limited pleural disease and the primary site of disease in a good-risk patient.

\section{Reference}

1. Li C, Kuo SW, Hsu HH, Lin MW, Chen JS. Lung adenocarcinoma with intraoper atively diagnosed pleural seeding: Is main tumor resection beneficial for prognosis? J Thorac Cardiovasc Surg. 2018;155:1238-49. 